\title{
Iron deficiency anaemia: pathophysiology, assessment, practical management
}

\author{
Aditi Kumar (D) , ${ }^{1}$ Esha Sharma, ${ }^{2}$ Alexandra Marley, ${ }^{1}$ Mark A Samaan, ${ }^{2}$ \\ Matthew James Brookes (1) 1,3
}

To cite: Kumar A, Sharma E, Marley A, et al. Iron deficiency anaemia: pathophysiology, assessment, practical management. BMJ Open Gastro 2022;9:e000759. doi:10.1136/ bmjgast-2021-000759

Received 16 November 2021 Accepted 20 December 2021

Check for updates

(C) Author(s) (or their employer(s)) 2022. Re-use permitted under CC BY-NC. No commercial re-use. See rights and permissions. Published by BMJ.

${ }^{1}$ Department of Gastroenterology, The Royal Wolverhampton NHS Trust, Wolverhampton, UK ${ }^{2}$ Inflammatory Bowel Disease Unit, Guys and St Thomas' NHS Foundation Trust, London, UK ${ }^{3}$ Research Institue, Faculty of Science and Engineering, University of Wolverhampton, Wolverhampton, UK

Correspondence to Dr Aditi Kumar; aditikumar@nhs.net

\section{ABSTRACT}

The WHO has recognised iron deficiency anaemia (IDA) as the most common nutritional deficiency in the world, with $30 \%$ of the population being affected with this condition. Although the most common causes of IDA are gastrointestinal bleeding and menstruation in women, decreased dietary iron and decreased iron absorption are also culpable causes. Patients with IDA should be treated with the aim of replenishing iron stores and returning the haemoglobin to a normal level. This has shown to improve quality of life, morbidity, prognosis in chronic disease and outcomes in pregnancy. Iron deficiency occurs in many chronic inflammatory conditions, including congestive cardiac failure, chronic kidney disease and inflammatory bowel disease. This article will provide an updated overview on diagnosis and management of IDA in patients with chronic conditions, preoperative and in pregnancy. We will discuss the benefits and limitations of oral versus intravenous iron replacement in each cohort, with an overview on cost analysis between the different iron formulations currently on the market.

\section{INTRODUCTION}

The WHO has recognised iron deficiency anaemia (IDA) as the most common nutritional deficiency in the world, with $30 \%$ of the population being affected with this condition. ${ }^{1}$ While IDA is more prevalent in children and women, adult men are also susceptible depending on their socioeconomic status and health conditions. ${ }^{2}$ Although the most common causes of IDA are gastrointestinal (GI) bleeding and menstruation in women, decreased dietary iron intake and absorption are also culpable causes. ${ }^{3}$

Iron is required for various cellular functions, including but not limited to enzymatic processes, DNA synthesis, oxygen transport and mitochondrial energy generation. ${ }^{45}$ As such, the symptoms of IDA can vary over a wide range. Shortness of breath, fatigue, palpitations, tachycardia and angina can result from reduced blood oxygen levels. This resultant hypoxemia can subsequently cause a compensatory decrease in intestinal blood flow, leading to motility disorder, malabsorption, nausea, weight loss and abdominal pain. Central hypoxia can cause headaches, vertigo and lethargy as well as cognitive impairment with several studies showing an improvement in cognitive functions once anaemia has normalised. ${ }^{6-9}$ It is well known that IDA significantly affects quality of life $(\mathrm{QoL})^{9}$ with recent evidence demonstrating that treating IDA improves QoL, regardless of the underlying cause for anaemia. ${ }^{810}$

In this review, we will discuss the pathophysiology, diagnosis, treatment and complications in the management of IDA. The investigative criteria for IDA are beyond the scope of this article and have been comprehensively outlined in the recent British Society of Gastroenterology guidelines. ${ }^{11}$

\section{Pathophysiology}

Iron is an essential element and is controlled primarily by dietary intake, intestinal absorption and iron recycling. ${ }^{12}$ Dietary iron can be found in two forms: haem and non-haem iron. Haem iron is easily absorbable and arises from haemoglobin $(\mathrm{Hb})$ and myoglobin in the form of animal meat, poultry and fish. Nonhaem iron is mostly found in plant food but is not as easily absorbable. Compounds such as phytate, oxalate, polyphenols and tannin, which are found in plants, diminish the uptake of non-haem iron, as do some drugs, such as proton pump inhibitors. ${ }^{13} 14$ Ascorbic acid, citrate and gastric acid, conversely, facilitate iron absorption. ${ }^{15}$ In a healthy diet, approximately $5-15 \mathrm{mg}$ of elemental iron and $1-5 \mathrm{mg}$ of haem iron are ingested daily although only $1-2 \mathrm{mg}$ is ultimately absorbed into the intestine, predominantly in the duodenum and proximal jejunum. ${ }^{16}$ Please see figure 1 for details on the iron absorption pathways.

\section{Assessment and diagnosis}

The WHO defines anaemia as blood $\mathrm{Hb}$ level below $130 \mathrm{~g} / \mathrm{L}$ in men and $120 \mathrm{~g} / \mathrm{L}$ in women. ${ }^{1}$ In isolated iron deficiency, serum 


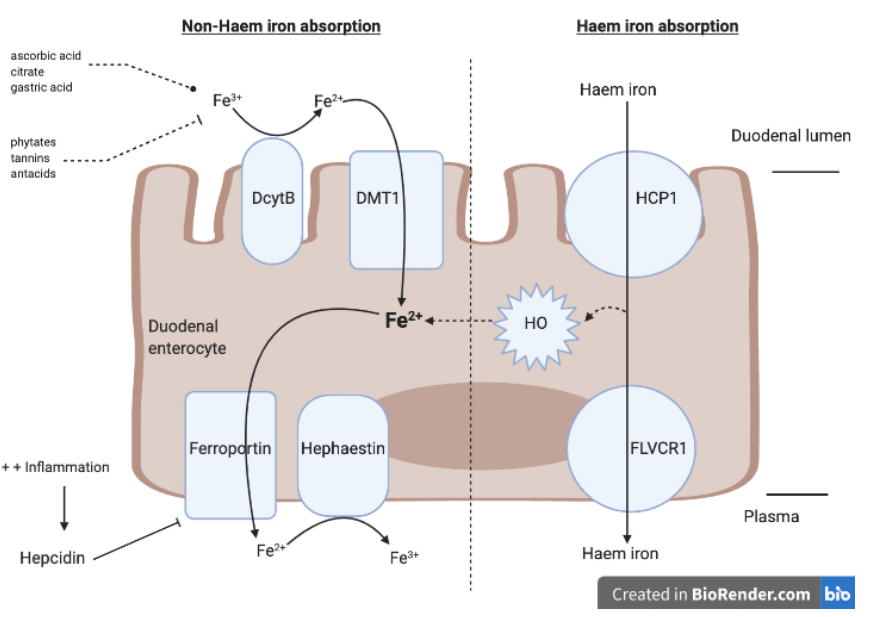

Figure 1 The two different iron absorption pathways. Nonhaem absorption pathway (left): insoluble ferric iron $\left(\mathrm{Fe}^{3+}\right)$ is reduced to absorbable ferrous iron $\left(\mathrm{Fe}^{2+}\right)$, which is carried out by the enzyme duodenal cytochrome $B$ (DcytB). The divalent metal transporter 1 (DMT1) imports $\mathrm{Fe}^{2+}$ across the apical surface and into the cell, which can then be either stored as ferritin or exported into circulation through ferroportin. Prior to exiting the enterocyte, $\mathrm{Fe}^{2+}$ must be oxidised back to $\mathrm{Fe}^{3+}$ by hephaestin or ceruloplasmin. Haem absorption pathway (right): the haem carrier protein (HCP1) transports haem iron directly into the enterocyte. Once inside the enterocyte, haem iron can either be released into plasma via the haem exporter FLVCR1 or be converted back into $\mathrm{Fe}^{2+}$ via the haem oxidase $(\mathrm{HO})$ enzyme. The ferroportin receptor then releases $\mathrm{Fe}^{2+}$ into the plasma. Hepcidin, a hepatic peptide hormone, controls ferroportin, the sole iron exporter, by promoting its endocytosis. Hepcidin production and circulation are regulated by plasma iron concentration and iron stores. Hepcidin is increased in the presence of inflammation, which then promotes the degradation of ferroportin and subsequently impairs the exportation of cellular iron into plasma. Figure taken with permission from Kumar and Brookes. $^{84}$

ferritin (the storage molecule for iron) should be less than $30 \mathrm{ug} / \mathrm{L} .{ }^{17}$ However, ferritin is an acute phase protein and can be increased in the presence of inflammation. ${ }^{18}$ Thus, if there is evidence of concomitant inflammation, such as elevated $\mathrm{C}$ reactive protein, ferritin less than $100 \mathrm{ug} / \mathrm{L}$ is indicative of IDA. ${ }^{19}$ Transferrin, the iron transporter, is generally elevated; however, it is a negative acute phase protein and, therefore, can be normal or reduced in chronic inflammatory states. ${ }^{20}$ Serum iron and transferrin saturations (TSAT) will be reduced with TSAT less than $20 \%$ required for the diagnosis of IDA. ${ }^{17}$ See table 1 for the breakdown of diagnostic criteria for IDA. It is crucial to note that iron deficiency should not be excluded in the presence of a normal $\mathrm{Hb}$ as a significant amount of iron must be lost before the $\mathrm{Hb}$ levels begin to decline. Thus, a low mean corpuscular $\mathrm{Hb}$ with a normal $\mathrm{Hb}$ or an increase in red cell distribution width signifies mild iron deficiency without anaemia. ${ }^{21}$

\section{Management}

Patients with IDA should be treated with the aim of replenishing iron stores and returning the $\mathrm{Hb}$ to a normal level.
Table 1 Diagnostic criteria for iron deficiency anaemia

\begin{tabular}{|c|c|}
\hline Serum markers & Diagnosis for IDA \\
\hline Haemoglobin & $\begin{array}{l}<130 \mathrm{~g} / \mathrm{L} \text { males } \\
<120 \mathrm{~g} / \mathrm{L} \text { females } \\
<110 \mathrm{~g} / \mathrm{L} \text { in pregnancy }\end{array}$ \\
\hline Ferritin* & $\begin{array}{l}<30 \mathrm{ug} / \mathrm{L} \text { if no inflammation } \\
<100 \mathrm{ug} / \mathrm{L} \text { if inflammation }\end{array}$ \\
\hline Transferrin $†$ & Raised \\
\hline Total iron binding capacity & Raised \\
\hline Iron & Reduced \\
\hline Transferrin saturations & $<20 \%$ \\
\hline Mean corpuscular volume & Low \\
\hline
\end{tabular}

*Is an positive acute phase protein and can be raised in inflammatory conditions.

†ls a negative acute phase protein and can be normal or reduced in inflammatory conditions.

IBD, inflammatory bowel disease.

This has been shown to improve QoL, morbidity, prognosis in chronic disease and outcomes in pregnancy. ${ }^{22}$ Iron replenishment can occur via three routes: oral iron, parenteral oral and transfusion of packed red cells. Each route has its benefits and limitations, which will be discussed below in greater detail.

\section{Conventional oral iron formulations}

The British Society of Gastroenterology recommends ferrous preparations, specifically ferrous sulphate, as first-line therapy for iron replenishment as they are cheap, have good bioavailability, available in multiple preparations and have been shown to replenish iron stores and correct anaemia effectively. ${ }^{11}$ However, there are also many limitations to their use, with the most common being the frequency and severity of side effects. A systematic review demonstrated that GI side effects were the most problematic with constipation being the most frequent complaint, followed by nausea and diarrhoea. ${ }^{23}$ This will have a resultant effect on patient adherence, likely leading to cessation and, thus, inadequate treatment. $^{24}$

The appropriate dosing of ferrous iron preparations is also a contentious issue between clinicians. To adequately replenish iron stores, therapeutic treatment of IDA was initially felt to require $200 \mathrm{mg}$ of iron sulphate 2-3 times per day in order to raise $\mathrm{Hb}$ by $20 \mathrm{~g}$ / L over a 4-week period, with treatment continuing for 3 months. ${ }^{25}$ However, the daily doses of elemental iron should not be greater than $100 \mathrm{mg} /$ day $^{26}$ as the body can only absorb $10-20 \mathrm{mg}$ of iron per day. ${ }^{26}$ It should be noted that $200 \mathrm{mg}$ of ferrous sulphate is equivalent to $65 \mathrm{mg}$ of elemental iron. ${ }^{27}$

A recent study compared oral iron dosing regimens in women with mild anaemia with divided daily, once daily and alternate-day dosing. The results demonstrated superiority with alternate-day dosing, with $33 \%$ greater fractional iron absorption over 14 doses. ${ }^{28}$ In addition, 
a randomised trial of elderly patients with IDA received $15 \mathrm{mg}, 50 \mathrm{mg}$ or $150 \mathrm{mg}$ of elemental iron per day. After 2 months, the mean increase in $\mathrm{Hb}$ was the same in all groups $(1.4 \mathrm{~g} / \mathrm{dL})$; however, adverse effects were significantly greater with higher doses. ${ }^{29}$ It is, therefore, an evolving view that a single daily dose $(40-60 \mathrm{mg})$ or a slightly higher alternate-day dose $(80-100 \mathrm{mg})$ is the preferred dosing regimen in order to reduce the side effects and optimise the proportion of elemental iron absorbed. ${ }^{28-30}$

Sodium feredetate is a water-soluble EDTA compound with higher bioavailability than the ferrous iron salt preparations. In the UK, it is available as a liquid preparation (Sytron); however, it is also available in tablet form (Ecofer, not currently licensed in the UK) often in combination with B12 and folate. ${ }^{31}$ In a study looking at treatment of IDA in pregnant women, sodium feredetate increased $\mathrm{Hb}$ by $1.28 \mathrm{~g} / \mathrm{dL}$ after 1 month of treatment and $2.11 \mathrm{~g} /$ $\mathrm{dL}$ after 2 months of treatment. This was in comparison to the group of women who received ferrous sulphate, where the mean $\mathrm{Hb}$ rose by $1 \mathrm{~g} / \mathrm{dL}$ after 1 month and $1.58 \mathrm{~g} / \mathrm{dL}$ after 2 months. As well as a significantly greater increase in $\mathrm{Hb}$, there were significantly fewer side effects seen with sodium feredetate than ferrous sulphate. ${ }^{32}$ This study also highlighted the improved bioavailability of sodium feredetate as this cohort was given one $231 \mathrm{mg}$ tablet once per day for 2 months (equivalent to $33 \mathrm{mg}$ of elemental iron) compared with the ferrous sulphate cohort who were given $200 \mathrm{mg}$ tablets two times per day for 2 months (equivalent to $60 \mathrm{mg}$ of elemental iron).

\section{Novel oral iron formulations}

Ferric maltol, a novel preparation, is a non-salt oral iron formulation composed of stable ferric iron complexed with a sugar derivative, tri-maltol. It is licenced in the European Union and the USA and sold under the brand names Feraccru and Accrufer, respectively. When absorbed, the maltol ligand remains complexed to iron, which reduces the formation of free iron and facilitates iron transport across the enterocyte. ${ }^{33}$ This subsequently increases the bioavailability of iron such that lower doses of elemental iron are required to treat IDA compared with the ferrous iron preparations. ${ }^{34}$ Furthermore, ferric maltol has been shown to have less of an effect on the gut microbiome. ${ }^{35}$ Studies on the use of ferric maltol has been limited to patients with inflammatory bowel disease (IBD), with results demonstrating improvement in $\mathrm{Hb}$ levels beyond 12 weeks with sustained normal $\mathrm{Hb}$ levels up to 64 weeks when compared with placebo. ${ }^{36} 37$ When compared with intravenous ferric carboxymaltose, however, ferric maltol was shown to be inferior and did not meet the primary endpoint of increasing $\mathrm{Hb}$ by $2 \mathrm{~g} / \mathrm{L}$ or $\mathrm{Hb}$ normalisation by 12 weeks ( $85 \%$ vs $68 \%$, respectively). ${ }^{38}$

Finally, sucrosomial iron is an innovative oral ironcontaining carrier, in which ferric pyrophosphate is within a phospholipid bilayer membrane forming the 'sucrosome', creating a gastroresistant complex, which can be transported to the intestinal mucosa where it is absorbed without free iron interacting with the gut wall. ${ }^{39} 40$ This unique structure protects iron from the acidic environment in the stomach, increases intestinal epithelial absorption and ensures high bioavailability while reducing the risk for potential adverse GI effects. ${ }^{39}$ Despite lower doses of elemental iron, this newer oral iron preparation $(30-60 \mathrm{mg} /$ day) has also shown greater efficacy in increasing $\mathrm{Hb}$ and ferritin concentrations compared with ferrous sulphate (105-210 mg/day), with a mean $\mathrm{Hb}$ increase in $2.7 \mathrm{~g} / \mathrm{dL}$ and $1.4 \mathrm{~g} / \mathrm{dL}$, respectively, over a 12-week course of treatment. ${ }^{39}$

Recent studies have demonstrated sucrosomial iron to be non-inferior to parenteral iron in patients with anaemia secondary to coeliac disease, cancer, bariatric surgery and chronic kidney disease (CKD) ${ }^{41-43}$ In a study looking at patients with IDA as a result of benign GI or gynaecological bleeding who had previously not responded to or not tolerated ferrous sulphate were randomised to receive a high dose of either sucrosomial iron or intravenous ferrous gluconate. Results demonstrated that patients were comparable at baseline and rise in $\mathrm{Hb}$ was not significantly different between the two groups, with the number of weeks required to achieve an $\mathrm{Hb}$ target value of $12 \mathrm{~g} / \mathrm{dL}$ was four in the sucrosomial iron group and 3.5 in the ferrous gluconate group. ${ }^{44}$

\section{Intravenous iron}

An alternative to oral iron supplementation is parenteral administration. Intravenous iron is the preferred route of administration in some patients and is increasingly favoured due to its rapid correction of $\mathrm{Hb}$, fewer side effects and improved safety profile. The primary advantage of intravenous iron is that it bypasses the GI tract absorption, thereby avoiding further mucosal aggravation and inflammation and producing less side effects. ${ }^{45}$ Clinicians also do not have to worry about patient's adherence to medication.

There are a variety of intravenous iron preparations with selection of the agent dependent on multiple factors including cost considerations, patient and physician preference and product availability. It is important to note that clinical studies of the various formulations follow different protocols, and as of yet, there are no large headto-head trials between these formulations comparing efficacy and safety profile.

Older intravenous iron preparations such as highmolecular weight dextran iron (Dexferrum) have been discontinued due to their unfavourable safety profiles with relatively high incidence of anaphylaxis. ${ }^{46}$ The lower molecular weight dextran compounds such as Cosmofer are, however, still in use and have been shown to be effective with a much lower incidence of anaphylactoid reactions. ${ }^{47}$ While there has not been a study comparing the different preparations, a meta-analysis looking at the overall rate of anaphylaxis with intravenous dextran was $0.61 \%,{ }^{48}$ which is significantly greater than with the newer non-dextran intravenous preparations. ${ }^{49}$ 
Ferric derisomaltose (Monofer) is an alternative intravenous iron preparation, which is often preferred to Cosmofer due to its shorter infusion time, thereby optimising the use of medical infusion units and nursing time as these drugs are often given as day-case procedures. Monofer is also preferred by some as it can be given as one infusion rather than two infusions. Ferric carboxymaltol (Ferinject) is a preparation widely used in the UK. It can be safely administered at a single dose of $1000 \mathrm{mg}$ within $15 \mathrm{~min}$; however, two infusions may be required in some patients, depending on their weight and $\mathrm{Hb}$ levels. Finally, iron sucrose (Venofer) is given by a slow injection of $100-200 \mathrm{mg} 2-3$ times a week. ${ }^{50}$ It has been shown to be effective, although a comparison study showed Ferinject to be superior. In this study, Ferinject was associated with a higher rate of achieving a $2 \mathrm{~g} / \mathrm{dL}$ increase in $\mathrm{Hb}$ concentration in comparison to iron sucrose by a relative risk of $1.65 .{ }^{51}$ While Venofer has been extensively studied, the major drawback in its use is the need for multiple infusions, which can not only be less acceptable to patients but also made difficult for overstretched healthcare services.

\section{Red blood cell transfusion}

It is advised that transfusions should be reserved for patients with severe anaemia, haemodynamically unstable and/or have associated comorbid conditions. ${ }^{26}$ However, while severe anaemia is defined as $\mathrm{Hb}<70 \mathrm{~g} / \mathrm{dL}$, many of these patients may be haemodynamically stable and rather have chronic anaemia, remaining asymptomatic. Although a unit of blood contains approximately $200 \mathrm{mg}$ of iron, ${ }^{22}$ these patients are very likely to require further iron supplementation to adequately replenish their iron stores, particularly if the cause for their anaemia is chronic and not easily treatable, for example, advanced malignancy or haematological disease.

Clinicians are rightly reluctant to transfuse patients unnecessarily as it is associated with not insignificant risks. These include an increased mortality with liberal blood transfusion in the setting of upper GI bleeding. ${ }^{52}$ There is also increased incidence of transfusion-related reactions. This includes the risk of Transfusion Related Acute Lung Injury, which is one of the most serious reactions, the incidence of which is approximately 1 in 5000 transfusions. ${ }^{53}$ Furthermore, there remains a small risk for transmitting infections, both viral and bacterial. ${ }^{54-56}$

\section{Considerations in management} Comorbidities

IDA occurs in many chronic inflammatory conditions, including congestive cardiac failure (CCF), CKD and IBD (table 2). To complicate matters, symptoms such as fatigue are commonly seen in these conditions, which can mimic and be confused with symptoms of IDA. Consequently, the management of IDA can often be overlooked. Untreated IDA can have greater consequences in these conditions causing an exacerbation of the underlying disease. ${ }^{6}$

\section{Congestive cardiac failure}

In CCF, IDA is one of the most prevalent comorbid conditions ${ }^{57}$ and can be a result of multiple factors including reduced appetite, increased GI blood losses as a result of antiplatelet or anticoagulant medication and decreased GI absorption due to oedema. ${ }^{58}$

Table 2 A list of common conditions and patient groups who have an increased risk of developing iron deficiency anaemia

\begin{tabular}{|c|c|c|c|}
\hline Background & $\begin{array}{l}\text { Cause of iron deficiency } \\
\text { anaemia }\end{array}$ & Cause of blood loss & $\begin{array}{l}\text { Recommended route of iron } \\
\text { replacement }\end{array}$ \\
\hline Congestive cardiac ailure & $\begin{array}{l}\text { Poor nutrition } \\
\text { Decreased Gl absorption }\end{array}$ & $\begin{array}{l}\text { Antiplatelet and/or anticoagulant } \\
\text { use }\end{array}$ & Intravenous \\
\hline Chronic kidney disease & & $\begin{array}{l}\text { Dialysis and frequent blood } \\
\text { sampling }\end{array}$ & Intravenous \\
\hline Inflammatory bowel disease & & $\begin{array}{l}\text { Chronically inflamed and ulcerated } \\
\text { bowel }\end{array}$ & Intravenous \\
\hline Elderly & & $\begin{array}{l}\text { Medications (antiplatelet, } \\
\text { anticoagulant, anti-inflammatories, } \\
\text { anti-depressants) }\end{array}$ & Oral \\
\hline Malignancy & $\begin{array}{l}\text { Poor nutrition } \\
\text { Loss of healthy blood cells } \\
\text { Damage to the bone } \\
\text { marrow }\end{array}$ & Bleeding tumour & Intravenous \\
\hline Pregnancy & $\begin{array}{l}\text { Poor nutrition } \\
\text { Increased iron demands to } \\
\text { mother and fetus }\end{array}$ & - & Intravenous or oral \\
\hline
\end{tabular}

The cause for iron deficiency anaemia, including causes for increased blood loss, and the recommended route of iron replacement are listed. 
The median dose of iron needed to replete iron sufficiently in patients with CCF with IDA is $1000 \mathrm{mg} .{ }^{59}$ If patients were given ferrous sulphate, the first-line oral preparation, the bioavailability is only $10 \%$ at best, ${ }^{60}$ and, thus, patients would need a minimum of 50 days at a dose of $200 \mathrm{mg} /$ day to correct the iron deficit. Realistically, considering missed doses or non-adherence, it can take up to 6 months to adequately replenish iron stores. ${ }^{58}$ Thus, intravenous iron should be considered first line for the treatment of iron deficiency in $\mathrm{CCF}^{6}$ The Ferinject Assessment in Patients with Iron Deficiency and Heart Failure (FAIR-HF) and Ferric Carboxymaltose Evaluation on Performance in Patients with Iron Deficiency in Combination with Chronic Heart Failure (CONFIRM-HF) trials demonstrated the benefit of ferric carboxymaltose compared with placebo in correcting IDA by improving exercise capacity, cardiac function, symptom severity and QoL. ${ }^{61}$

\section{Chronic kidney disease}

The causes of IDA in CKD are similar to those in CCF, namely, reduced GI iron absorption, poor nutrition and blood loss caused by dialysis and frequent blood sampling. A recent meta-analysis and systematic review demonstrated intravenous iron to be more effective than oral iron in treating IDA in CKD, regardless of requirement for dialysis. ${ }^{62}$ The Kidney Disease: Improving Global Outcomes clinical practice guidelines also recommend intravenous iron as first-line treatment for patients with stage $5 \mathrm{CKD} .{ }^{63}$ However, ferric citrate might be an alternative oral preparation with a recent trial of 203 patients given $1 \mathrm{~g}$ three times per day showing fewer hospitalisation rates and lower incidence of death, dialysis or transplantation. ${ }^{64}$ Despite the evidence provided for intravenous preparations, oral iron remains first-line therapy for many clinicians and patients as it is readily available, inexpensive and avoids the need for intravenous access, which can cause injury to blood vessels that may be needed in the future for critical vascular access. ${ }^{65}$ Furthermore, there are concerns regarding potential side effects with intravenous iron including anaphylaxis, hypersensitivity, susceptibility to infections and cardiovascular events, hypophosphataemia and iron overload. ${ }^{66}$ While human erythropoietin (EPO) and EPO-stimulating agents (ESA) have been in use for decades, they are associated with worsening hypertension, seizures and dialysis access clotting. ${ }^{6768}$ Moreover, ESA has not shown to reduce adverse outcomes associated with anaemia, including mortality rate, hospitalisations and progression of kidney disease. ${ }^{69}$

\section{Inflammatory bowel disease}

IDA has been acknowledged as one of the most common extra intestinal manifestations of IBD. ${ }^{20}$ Impaired GI iron absorption is caused by chronically inflamed bowel, chronic blood losses, bowel resection and malnutrition. ${ }^{6}$ Improvement in iron status through treatment with intravenous iron has led to significant improvement in QoL in patients with IBD. ${ }^{10}$ Adverse effects from oral iron are well recognised but have greater consequences in patients with IBD. Absorption from the GI tract is limited (on average 10\%-20\% of ingested amount) and unabsorbed iron is exposed to the ulcerated intestinal surface, which can cause further mucosal damage as well as changes to gut microbiota ${ }^{70}$ although it is not yet established whether oral iron exacerbates IBD inflammation beyond animal models. The European Crohn's and Colitis Organisation (ECCO) guidelines advise the use of intravenous iron as first-line therapy in patients with active disease, severe anaemia $(\mathrm{Hb}<100 \mathrm{~g} / \mathrm{L})$, if previously intolerant to oral iron and for patients in need of concomitant treatment with EPO. ${ }^{26}$ However, there is a place for both oral and intravenous iron in patients with IBD, which is further outlined in figure 2.

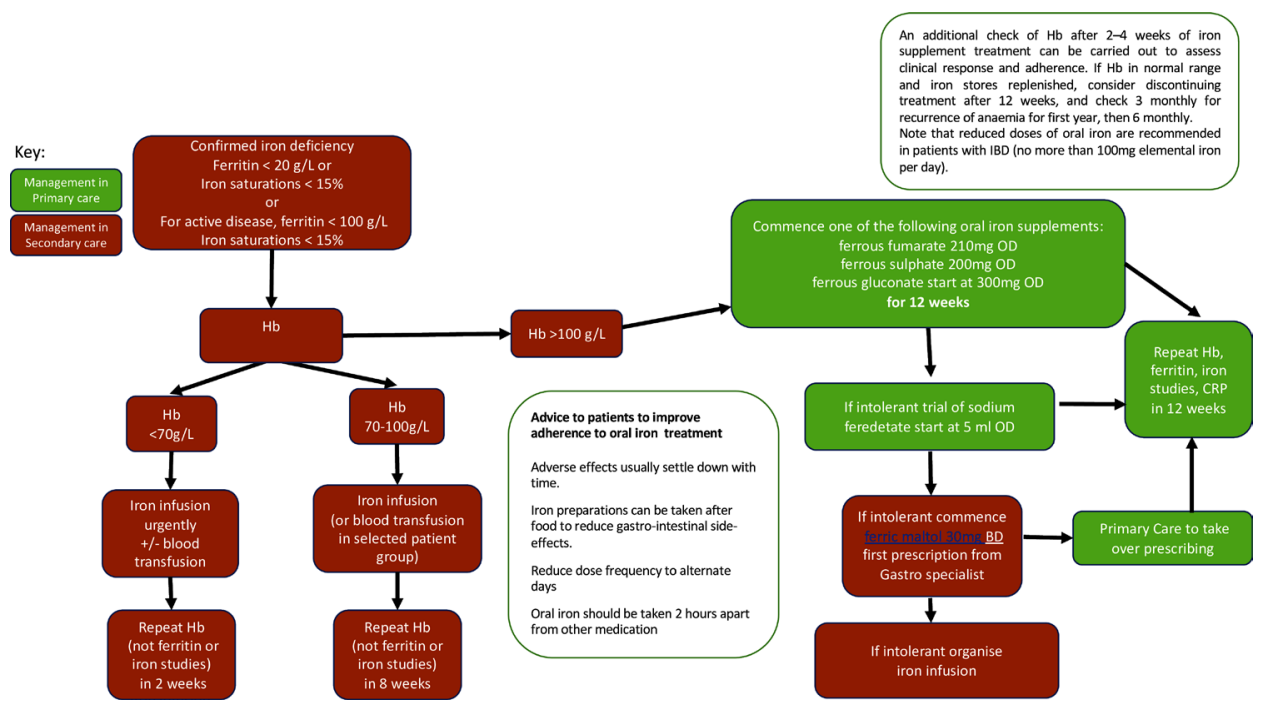

Figure 2 Iron deficiency treatment pathway in patients with IBD patients as followed by the South East London Clinical Commissioning Group. ${ }^{85} \mathrm{Hb}$, haemoglobin; IBD, inflammatory bowel disease. 


\section{Malignancy}

IDA is associated with multiple types of cancer, including GI (colorectal, pancreatic, oesophageal, gastric), lung, genitourinary (cervical, prostate, testicular), breast and haemotological (lymphoma, leukaemia, myeloma). ${ }^{71}$ In cancer patients, iron deficiency is associated with fatigue and weakness irrespective of the presence of anaemia. ${ }^{66}$ Iron deficiency can occur frequently by means of chemotherapy-induced anaemia and anaemia of chronic disease. ${ }^{66}$ Blood transfusions, ESA therapy and intravenous iron are the potential treatment options for IDA in patients with cancer. The aim is to improve QoL and reduce reliance on blood transfusions that are often associated with further multiorgan complications. Beneficial effects of ESAs are limited and both the European medicines agency and Food and Drug Administration have recommended restricting their use to patients with symptomatic anaemia and those undergoing specific chemotherapy. ${ }^{72}$ A consensus of cancer experts suggest intravenous iron should be used over oral iron supplementation due to reduced efficacy and poor tolerance and adherence in the latter. ${ }^{72}$ This is corroborated by a meta-analysis of 11 randomised studies, where intravenous iron had an improved haematopoietic response in chemotherapy-induced anaemia with no safety concerns and an overall reduction in blood transfusion requirement, compared with oral iron. ${ }^{73}$

\section{Elderly population}

Another high-risk population are the elderly where prevalence of iron deficiency increases rapidly with age due to reduce oral intake, poor absorption and excess loss. ${ }^{74}$ A meta-analysis of trial data shows treatment of iron deficiency with both oral and intravenous iron reduces blood transfusion requirements and increases $\mathrm{Hb}$ levels but does not significantly impact mortality ${ }^{68}$ Oral supplementation is recommended for treatment of IDA in this population, and lower doses of oral iron may be effective and better tolerated among elderly patients. For those whose oral treatment has been unsuccessful, intravenous treatment should be considered to avoid adverse effects and effectively treat anaemia. However, potential adaptations of oral therapy should also be considered such as liquid formulations or reducing dose frequency. ${ }^{74}$

\section{IDA in surgery}

There is a growing field of evidence to focus on the impact of iron deficiency on morbidity and mortality in the perioperative period. Recently published national guidance recommends that IDA should be identified and treated pre and postoperatively, ${ }^{75}$ whether that be via oral or intravenous iron supplementation. Intravenous iron is recommended for those who are unable to tolerate oral iron, those with functional iron deficiency and those with surgical procedures close to the time the IDA was diagnosed. ${ }^{75}$ Further research is necessary to assess the impact of the timing of iron replacement prior to surgery.
Pregnancy

Anaemia in pregnancy is defined as $\mathrm{Hb}<110 \mathrm{~g} / \mathrm{L}$ with ferritin levels $<100 \mu \mathrm{g} / \mathrm{L} .{ }^{11}$ The total iron loss in pregnancy approximately $1000 \mathrm{mg}$, and, thus, the recommended daily dietary allowance for iron in pregnancy is $27 \mathrm{mg}$ compared with $8 \mathrm{mg}$ in the adult non-pregnant population. ${ }^{76}$ The usual recommended dose of elemental iron is $80 \mathrm{mg}$, which is equivalent to $250 \mathrm{mg}$ of oral iron sulphate tablets. ${ }^{76}$ Intermittent oral iron has been reported to be effective as daily iron dosing in raising $\mathrm{Hb}$ levels and is associated with a lower incidence of adverse effects. ${ }^{77}$ However, a meta-analysis has demonstrated intravenous iron sucrose improved $\mathrm{Hb}$ (mean difference $7.17 \mathrm{~g} / \mathrm{L}$ ) and serum ferritin levels (mean difference $49.66 \mathrm{ug} / \mathrm{L}$ ) while ferric carboxymaltose improved $\mathrm{Hb}$ levels (mean difference $8.52 \mathrm{~g} / \mathrm{L}$ ), compared with oral ferrous sulphate. ${ }^{78}$ Furthermore, side effects were less common with the parenteral formulations, but included local pain, skin irritation and rarely allergic reactions.

\section{Adverse effects}

As previously discussed, the common adverse effects of oral iron are well known among healthcare professionals and patients. The potential adverse effects of intravenous iron have more recently been publicised as they become further researched and understood. The rare adverse effect of hypersensitivity reactions has been known for some time and have dictated specialised protocols and training for healthcare professionals routinely administering intravenous iron.

Hypophosphataemia is an increasingly recognised adverse effect of intravenous iron. The risk of persistent hypophosphataemia and osteomalacia is possibly higher with ferric carboxymaltose than with the other intravenous iron preparations. A key mechanism is the carbohydrate moieties in ferric carboxymaltose inhibit degradation of fibroblast growth factor 23, resulting in greater renal loss of phosphate. ${ }^{79}$ Phosphate replacement is an ineffective management strategy due to this mechanism as any phosphate replaced is lost through greater renal wasting. ${ }^{80}$ Although the clinical significance is not yet fully understood, it is expected to have more of an effect on those patients requiring higher doses, repeat courses and are at a higher risk of electrolyte imbalances due to malnutrition. ${ }^{79}$

A less commonly recognised adverse effect is that of extravasation of intravenous iron that can cause longlasting tattoo-like skin discolouration preceded by skin irritation and pain at the injection site. Though this adverse effect is considered to be rare (occurring at a rate of approximately $1.6 \%$ ), the skin staining can last for several months after the initial infusion despite pharmacological interventions to resolve the reaction. ${ }^{81} 82$ Though the extravasation of intravenous iron is not expected to cause harm, the long-lasting effects of the skin stain can have negative psychological and social impact on patients, so awareness of this phenomenon among healthcare professionals is imperative. Patients 
Table 3 Cost analysis per drug

\begin{tabular}{|c|c|c|c|c|c|}
\hline Drug (brand) & Form & $\begin{array}{l}\text { Time treatment course } \\
\text { provided in (weeks) }\end{array}$ & Infusion time & Administration visits & Cost (£) \\
\hline Ferrous sulphate* & Tablet & 12 & - & - & 2.43 \\
\hline Ferrous gluconate* & Tablet & 12 & - & - & 3.27 \\
\hline Ferrous fumarate* & Tablet & 12 & - & - & 2.47 \\
\hline Sodium feredate (Sytron) ${ }^{\star \star}$ & Liquid & 12 & - & - & 29.90 \\
\hline Ferric maltol (Ferracru) $†$ & Capsule & 12 & - & - & 142.80 \\
\hline $\begin{array}{l}\text { Ferric carboxymaltose } \\
\text { (Ferinject) } \ddagger\end{array}$ & Injection & 2 & 30 & 2 & 308.46 \\
\hline $\begin{array}{l}\text { Ferric derisomaltose } \\
\text { (Monofer) } \ddagger\end{array}$ & Injection & 2 & 30 & 2 & 339.00 \\
\hline Iron sucrose (Venofer)§ & Injection & 3 & 30 & 8 & 768.00 \\
\hline Iron dextran (Cosmofer)§ & Injection & 1 & 240 & 1 & 119.55 \\
\hline
\end{tabular}

National Health Service (NHS) indicative price as per British National Formulary (BNF).

${ }^{*}$ Cost based on one one tablet or $10 \mathrm{~mL}$ per day.

†Cost based on two capsules per day.

łBased on $70 \mathrm{~kg}$ patient, with $\mathrm{Hb}<10$ according to each summary of product characteristics.

$\S$ Based on $70 \mathrm{~kg}$ patient with $\mathrm{Hb}$ of $90 \mathrm{~g} / \mathrm{L}$.

$\mathrm{Hb}$, haemoglobin.

should be informed of this potential adverse effect prior to administration of intravenous iron.

\section{Cost implications}

It is important to consider both the cost of the impact of iron deficiency to the healthcare system and the cost of the individual treatments when assessing the overall cost of IDA management (table 3). Oral treatment with standard ferric salts is by far the lowest cost option with convenient administration and low drug cost (a 12-week course is approximately £2). Conversely, intravenous iron preparations can cost approximately $£ 1400$ per patient infusion when based on the highest iron requirement and including costs to the healthcare system for patient day-case admission. However, the most significant cost to the healthcare system is that of untreated IDA, which can result in emergency hospitalisation and multiple blood transfusions, approximately $£ 1700$ per admission on average. Brookes et al reviewed management of IDA in England between 2012 and 2018 and identified that $£ 42.4$ million was spent on emergency hospital admissions. In comparison, $£ 46$ million was spent on day case admissions, although four times as many patients were treated in the outpatient setting. ${ }^{83}$ Though intravenous iron administration can seem more expensive than oral treatment, these findings strongly suggest that there is a need for a national strategy for standardising and streamlining elective intravenous iron administration to prevent more costly emergency admissions. For those who have not tolerated standard oral supplementation, ferric maltol may offer a more suitable alternative than intravenous iron. The cost of ferric maltol is significantly more than the standard oral iron (approximately $£ 170$ for a 12-week course) but much less than intravenous iron. If oral intolerance is the drive for choosing intravenous treatment, then ferric maltol may offer an alternative choice with less potential adverse effects, although direct comparisons of this drug with other iron formulations still need to be studied.

\section{Looking to the future: service development and redesign}

IDA is the most common nutritional disorder globally and is associated with multiple comorbid states with severe implications in QoL. Despite national guidance on managing IDA, there is still wide variability in current practices, not just between National Health Service trusts but also between clinicians and departments. Choosing between intravenous and oral iron therapies is dependent on many factors, including the therapy goal, response to prior therapy, patient preference, cost and ease of access to an infusion centre. A standardised pathway steered by evidence-based medicine can reduce this variance in care, while simultaneously supporting cost-effective anaemia management across and between the new integrated care systems.

Twitter Aditi Kumar @dr_dee_kumar

Contributors AK, AM and ES wrote the manuscript. MAS and MJB provided critical revisions of the manuscript. All authors have read and agreed to the published version of the manuscript.

Funding The authors have not declared a specific grant for this research from any funding agency in the public, commercial or not-for-profit sectors.

Competing interests ES served as a speaker and/or an advisory board member for Takeda, Janssen and Pharmacosmos. MAS served as a speaker, a consultant and/or an advisory board member for Abbvie, Bristol Myers Squibb, Sandoz, Janssen, Takeda, MSD, Falk and Samsung Bioepis. MJB has received funding from Vifor International and Tillotts Pharma in the form of grants for research work and travel expenses, outside of the submitted work.

Patient consent for publication Not applicable.

Ethics approval This study does not involve human participants.

Provenance and peer review Commissioned; externally peer reviewed. 
Data availability statement No data are available.

Open access This is an open access article distributed in accordance with the Creative Commons Attribution Non Commercial (CC BY-NC 4.0) license, which permits others to distribute, remix, adapt, build upon this work non-commercially, and license their derivative works on different terms, provided the original work is properly cited, appropriate credit is given, any changes made indicated, and the use is non-commercial. See: http://creativecommons.org/licenses/by-nc/4.0/.

ORCID iDs

Aditi Kumar http://orcid.org/0000-0003-1026-3173

Matthew James Brookes http://orcid.org/0000-0002-8782-0292

\section{REFERENCES}

1 World Health Organisation. Haemoglobin concentrations for the diagnosis of anaemia and assessment of severity. Vitamin and Mineral Nutrition Information System 2011 https://www.who.int/ vmnis/indicators/haemoglobin.pdf

2 Bathla S, Arora S. Prevalence and approaches to manage iron deficiency anemia (IDA). Crit Rev Food Sci Nutr 2021:1-14.

3 Shokrgozar N, Golafshan HA. Molecular perspective of iron uptake, related diseases, and treatments. Blood Res 2019;54:10-16.

4 Lopez A, Cacoub P, Macdougall IC, et al. Iron deficiency anaemia. Lancet 2016:387:907-16.

5 Crielaard BJ, Lammers T, Rivella S. Targeting iron metabolism in drug discovery and delivery. Nat Rev Drug Discov 2017;16:400-23.

6 Cappellini MD, Comin-Colet J, de Francisco A, et al. Iron deficiency across chronic inflammatory conditions: international expert opinion on definition, diagnosis, and management. Am J Hematol 2017;92:1068-78

7 Çekiç C, İpek S, Aslan F, et al. The effect of intravenous iron treatment on quality of life in inflammatory bowel disease patients with nonanemic iron deficiency. Gastroenterol Res Pract 2015;2015:p. 582163.

8 García-López S, Bocos JM, Gisbert JP, et al. High-Dose intravenous treatment in iron deficiency anaemia in inflammatory bowel disease: early efficacy and impact on quality of life. Blood Transfus 2016;14:199-205.

9 Andro M, Le Squere P, Estivin S, et al. Anaemia and cognitive performances in the elderly: a systematic review. Eur J Neurol 2013;20:1234-40

10 Gisbert JP, Bermejo F, Pajares R, et al. Oral and intravenous iron treatment in inflammatory bowel disease: hematological response and quality of life improvement. Inflamm Bowel Dis 2009;15:1485-91.

11 Snook J, Bhala N, Beales ILP, et al. British Society of gastroenterology guidelines for the management of iron deficiency anaemia in adults. Gut 2021;70:2030-51.

12 Shah Y, Patel D, Khan N. Iron deficiency anemia in IBD: an overlooked comorbidity. Expert Rev Gastroenterol Hepatol 2021;15:771-81.

13 Hallberg L, Rossander L, Skånberg AB. Phytates and the inhibitory effect of bran on iron absorption in man. Am J Clin Nutr 1987;45:988-96.

14 Disler PB, Lynch SR, Charlton RW, et al. The effect of tea on iron absorption. Gut 1975;16:193-200.

15 Gulec S, Anderson GJ, Collins JF. Mechanistic and regulatory aspects of intestinal iron absorption. Am J Physiol Gastrointest Liver Physiol 2014;307:G397-409.

16 Monsen ER, Hallberg L, Layrisse M, et al. Estimation of available dietary iron. Am J Clin Nutr 1978;31:134-41.

17 Stein J, Dignass AU. Management of iron deficiency anemia in inflammatory bowel disease - a practical approach. Ann Gastroenterol 2013;26:104-13.

18 de Silva AD, Mylonaki M, Rampton DS. Oral iron therapy in inflammatory bowel disease: usage, tolerance, and efficacy. Inflamm Bowel Dis 2003;9:316-20.

19 Weiss G. Anemia of chronic disorders: new diagnostic tools and new treatment strategies. Semin Hematol 2015;52:313-20.

20 Jimenez KM, Gasche C. Management of iron deficiency anaemia in inflammatory bowel disease. Acta Haematol 2019;142:30-6.

21 Reinisch W, Staun M, Bhandari S, et al. State of the iron: how to diagnose and efficiently treat iron deficiency anemia in inflammatory bowel disease. J Crohns Colitis 2013;7:429-40.

22 Camaschella C. Iron deficiency. Blood 2019;133:30-9.

23 Tolkien Z, Stecher L, Mander AP, et al. Ferrous sulfate supplementation causes significant gastrointestinal side-effects in adults: a systematic review and meta-analysis. PLoS One 2015;10:e0117383.

24 Pasricha S-R, Tye-Din J, Muckenthaler MU, et al. Iron deficiency. Lancet 2021;397:233-48.

25 Summary of product characteristics (SMPC): ferrous sulfate tablets 200mg, 2020. Available: https://www.medicines.org.uk/emc/product/ 4231/smpc\#gref

26 Dignass AU, Gasche C, Bettenworth D, et al. European consensus on the diagnosis and management of iron deficiency and anaemia in inflammatory bowel diseases. J Crohns Colitis 2015;9:211-22.

27 compendium, E.m. Summary of product characteristics (SMPC): ferrous sulfate tablets $200 \mathrm{mg}$. Available: https://www.medicines.org. uk/emc/product/4231/smpc\#gref

28 Stoffel NU, Zeder C, Brittenham GM, et al. Iron absorption from supplements is greater with alternate day than with consecutive day dosing in iron-deficient anemic women. Haematologica 2020;105:1232-9.

29 Rimon E, Kagansky N, Kagansky M, et al. Are we giving too much iron? low-dose iron therapy is effective in octogenarians. Am J Med 2005;118:1142-7.

30 Moretti D, Goede JS, Zeder C, et al. Oral iron supplements increase hepcidin and decrease iron absorption from daily or twice-daily doses in iron-depleted young women. Blood $2015 ; 126: 1981-9$.

31 Formulary BN. Sodium Feredetat. Available: https://www.nice.org. uk/bnf-uk-only

32 Revankar VM, Garg A, Garg A, et al. Efficacy of sodium feredetate versus ferrous sulfate in iron deficiency anemia in preganant women. Int J Reprod Contracept Obstet Gynecol 2017;6:1978.

33 Barrand MA, Callingham BA, Dobbin P, et al. Dissociation of a ferric maltol complex and its subsequent metabolism during absorption across the small intestine of the rat. Br J Pharmacol 1991;102:723-9.

34 Cancelo-Hidalgo MJ, Castelo-Branco C, Palacios S, et al. Tolerability of different oral iron supplements: a systematic review. Curr Med Res Opin 2013;29:291-303.

35 Pereira DIA, Bruggraber SFA, Faria N, et al. Nanoparticulate iron(III) oxo-hydroxide delivers safe iron that is well absorbed and utilised in humans. Nanomedicine 2014:10:1877-86.

36 Schmidt C, Ahmad T, Tulassay Z, et al. Ferric maltol therapy for iron deficiency anaemia in patients with inflammatory bowel disease: long-term extension data from a phase 3 study. Aliment Pharmacol Ther 2016;44:259-70.

37 Gasche C, Ahmad T, Tulassay Z, et al. Ferric maltol is effective in correcting iron deficiency anemia in patients with inflammatory bowel disease: results from a phase- 3 clinical trial program. Inflamm Bowel Dis 2015;21:579-88.

38 Howaldt Set al. Long-Term effectiveness of oral ferric maltol vs intravenous ferric carboxymaltose for the treatment of irondeficiency anemia in patients with inflammatory bowel disease: a randomized controlled Noninferiority trial. Inflammatory Bowel Diseases 2021.

39 Bastida G, Herrera-de Guise C, Algaba A, et al. Sucrosomial iron supplementation for the treatment of iron deficiency anemia in inflammatory bowel disease patients refractory to oral iron treatment. Nutrients 2021;13. doi:10.3390/nu13061770. [Epub ahead of print: 22 May 2021].

40 Gómez-Ramírez S, Brilli E, Tarantino G, et al. Sucrosomial ${ }^{\circledR}$ iron: a new generation iron for improving oral supplementation. Pharmaceuticals 2018:11:97.

41 Mafodda A, Giuffrida D, Prestifilippo A, et al. Oral sucrosomial iron versus intravenous iron in anemic cancer patients without iron deficiency receiving darbepoetin alfa: a pilot study. Support Care Cancer 2017;25:2779-86.

42 Elli L, Ferretti F, Branchi F, et al. Sucrosomial iron supplementation in anemic patients with celiac disease not tolerating oral ferrous sulfate: a prospective study. Nutrients 2018:10:330.

43 Ciudin A, Simó-Servat O, Balibrea JM, et al. Response to oral sucrosomial iron supplementation in patients undergoing bariatric surgery. The BARI-FER study. Endocrinol Diabetes Nutr 2018;65:17-20.

44 Giordano G, Napolitano M, Di Battista V, et al. Oral high-dose sucrosomial iron vs intravenous iron in sideropenic anemia patients intolerant/refractory to iron sulfate: a multicentric randomized study. Ann Hematol 2021;100:2173-9.

45 Lee TW, Kolber MR, Fedorak RN, et al. Iron replacement therapy in inflammatory bowel disease patients with iron deficiency anemia: a systematic review and meta-analysis. J Crohns Colitis 2012;6:267-75

46 Rodgers GM, Auerbach M, Cella D, et al. High-Molecular weight iron dextran: a wolf in sheep's clothing? J Am Soc Nephrol 2008;19:833-4. 
47 Wysowski DK, Swartz L, Borders-Hemphill BV, et al. Use of parenteral iron products and serious anaphylactic-type reactions. Am J Hematol 2010;85:650-4.

48 Michael B, Coyne DW, Fishbane S, et al. Sodium ferric gluconate complex in hemodialysis patients: adverse reactions compared to placebo and iron dextran. Kidney Int 2002;61): :1830-9.

49 Wang C, Graham DJ, Kane RC, et al. Comparative risk of anaphylactic reactions associated with intravenous iron products. JAMA 2015;314): :2062-8.

50 Joint United Kingdom (UK) Blood Transfusion and Tissue Transplantation Services Professional Advisory Committee. Parenteral iron, 2014. Available: https://www.transfusionguidelines. org/transfusion-handbook/6-alternatives-and-adjuncts-to-bloodtransfusion/6-4-parenteral-iron

51 Evstatiev R, Marteau P, lqbal T, et al. FERGlcor, a randomized controlled trial on ferric carboxymaltose for iron deficiency anemia in inflammatory bowel disease. Gastroenterology 2011;141:e12:846-53.

52 Villanueva C, Colomo A, Bosch A, et al. Transfusion strategies for acute upper gastrointestinal bleeding. N Engl J Med 2013;368:11-21.

53 Bux J. Transfusion-related acute lung injury (TRALI): a serious adverse event of blood transfusion. Vox Sang 2005;89:1-10.

54 Bihl F, Castelli D, Marincola F, et al. Transfusion-Transmitted infections. J Trans/ Med 2007:5:25.

55 Guinet F, Carniel E, Leclercq A. Transfusion-Transmitted Yersinia enterocolitica sepsis. Clin Infect Dis 2011;53:583-91.

56 Kopko PM, Holland PV. Mechanisms of severe transfusion reactions. Transfus Clin Biol 2001;8:278-81.

57 Klip IT, Comin-Colet J, Voors AA, et al. Iron deficiency in chronic heart failure: an international pooled analysis. Am Heart $J$ 2013;165:575-82.

58 McDonagh T, Macdougall IC. Iron therapy for the treatment of iron deficiency in chronic heart failure: intravenous or oral? Eur J Heart Fail 2015;17:248-62.

59 Filippatos G, Farmakis D, Colet JC, et al. Intravenous ferric carboxymaltose in iron-deficient chronic heart failure patients with and without anaemia: a subanalysis of the FAIR-HF trial. Eur J Heart Fail 2013;15:1267-76.

60 Nielsen P, Kongi R, Buggisch P, et al. Bioavailability of oral iron drugs as judged by a 59Fe-whole-body counting technique in patients with iron deficiency anaemia. Therapeutic efficacy of iron(II)-glycine sulfate. Arzneimittelforschung 2005;55:376-81.

61 Ponikowski P, van Veldhuisen DJ, Comin-Colet J, et al. Rationale and design of the CONFIRM-HF study: a double-blind, randomized, placebo-controlled study to assess the effects of intravenous ferric carboxymaltose on functional capacity in patients with chronic heart failure and iron deficiency. ESC Heart Fail 2014;1:52-8.

62 Shepshelovich D, Rozen-Zvi B, Avni T, et al. Intravenous versus oral iron supplementation for the treatment of anemia in CKD: an updated systematic review and meta-analysis. Am J Kidney Dis 2016;68:677-90.

63 Locatelli F, Nissenson AR, Barrett BJ, et al. Clinical practice guidelines for anemia in chronic kidney disease: problems and solutions. A position statement from kidney disease: improving global outcomes (KDIGO). Kidney Int 2008;74:1237-40.

64 Block GA, Block MS, Smits G, et al. A pilot randomized trial of ferric citrate coordination complex for the treatment of advanced CKD. J Am Soc Nephrol 2019;30:1495-504.

65 Gutiérrez OM. Treatment of iron deficiency anemia in CKD and endstage kidney disease. Kidney Int Rep 2021;6:2261-9.
66 Kassianides X, Hazara AM, Bhandari S. Improving the safety of intravenous iron treatments for patients with chronic kidney disease. Expert Opin Drug Saf 2021;20:23-35.

67 Eschbach JW, Egrie JC, Downing MR, et al. Correction of the anemia of end-stage renal disease with recombinant human erythropoietin. Results of a combined phase I and II clinical trial. $N$ Engl J Med 1987;316:73-8.

68 Winearls CG, Oliver DO, Pippard MJ, et al. Effect of human erythropoietin derived from recombinant DNA on the anaemia of patients maintained by chronic haemodialysis. Lancet 1986;2:1175-8.

69 KDOQI, National Kidney Foundation. KDOQI clinical practice guidelines and clinical practice recommendations for anemia in chronic kidney disease. Am J Kidney Dis 2006;47:S11-145.

70 Kulnigg S, Gasche C. Systematic review: managing anaemia in Crohn's disease. Aliment Pharmacol Ther 2006;24:1507-23.

71 Naoum FA. Iron deficiency in cancer patients. Rev Bras Hematol Hemoter 2016;38:325-30.

72 Aapro M, Österborg A, Gascón P, et al. Prevalence and management of cancer-related anaemia, iron deficiency and the specific role of i.v. iron. Ann Oncol 2012;23:1954-62.

73 Gafter-Gvili A, Rozen-Zvi B, Vidal L, et al. Intravenous iron supplementation for the treatment of chemotherapy-induced anaemia - systematic review and meta-analysis of randomised controlled trials. Acta Oncol 2013;52:18-29.

74 Burton JK, Yates LC, Whyte L, et al. New horizons in iron deficiency anaemia in older adults. Age Ageing 2020;49:309-18.

75 Evidence, N.I.o.C. Perioperative care in adults (NICE guidance no 180), 2020. Available: https://www.nice.org.uk/guidance/ng180

76 Khalafallah AA, Dennis AE. Iron deficiency anaemia in pregnancy and postpartum: pathophysiology and effect of oral versus intravenous iron therapy. J Pregnancy 2012;2012:1-10.

77 Pena-Rosas JPet al. Intermittent oral iron supplementation during pregnancy. Cochrane Database Syst Rev 2015;10:CD009997.

78 Rogozińska E, Daru J, Nicolaides M, et al. Iron preparations for women of reproductive age with iron deficiency anaemia in pregnancy (FRIDA): a systematic review and network meta-analysis. Lancet Haematol 2021;8:e503-12.

79 Agency MaHpR. Ferric carboxymaltose: risk of symptomatic hypophosphataemia leading to osteomalacia and fractures, 2020. Available: https://www.gov.uk/drug-safety-update/ferriccarboxymaltose-ferinject-risk-of-symptomatic-hypophosphataemialeading-to-osteomalacia-and-fractures

80 Wolf M, Koch TA, Bregman DB. Effects of iron deficiency anemia and its treatment on fibroblast growth factor 23 and phosphate homeostasis in women. J Bone Miner Res 2013;28:1793-803.

81 Crowley CM, McMahon G, Desmond J, et al. Skin staining following intravenous iron infusion. BMJ Case Rep 2019;12. doi:10.1136/bcr2018-229113. [Epub ahead of print: 06 Jun 2019].

82 Harris RE, Garrick V, Curtis L, et al. Skin staining due to intravenous iron extravasation in a teenager with Crohn's disease. Arch Dis Child 2020;105:362.

83 Brookes MJ, Farr A, Phillips CJ, et al. Management of iron deficiency anaemia in secondary care across England between 2012 and 2018: a real-world analysis of hospital episode statistics. Frontline Gastroenterol 2021;12:363-9.

84 Kumar A, Brookes MJ. Iron therapy in inflammatory bowel disease. Nutrients 2020;12:3478.

85 Group, S.E.L.I.M.O.C.I.B.D.P.D. Iron deficiency treatment pathway for patients with IBD (pathway 5), 2019. Available: https:// selondonccg.nhs.uk/wp-content/uploads/dlm uploads/2021/09/ IBD-pathways-with-Fe-deficiency-pathway-June-2019-FINAL.pdf 